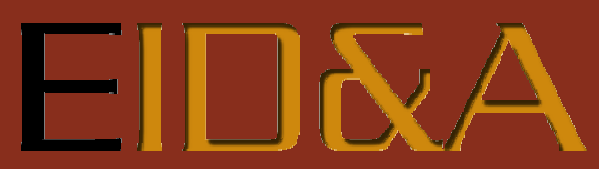

Revista Eletrônica de Estudos Integrados em Discurso e Argumentação

http://dx.doi.org/10.17648/eidea-15-1840

\title{
BRASIL, PÁTRIA EDUCADORA: MEMÓRIA DISCURSIVA E INTERDISCURSO NA TESSITURA DA LÍNGUA DE ESTADO
}

\author{
Tacia Rocha'; Luana Vitoriano-Gonçalves"; Flávia Cristina Silva Barbosa ${ }^{\mathrm{iii}}$
}

Resumo: A propaganda política utiliza técnicas de comunicação para materializar discursos partidários. O slogan é um exemplo, visto que mobiliza o funcionamento discursivo sobre as formas de governo do Estado, as ideologias partidárias, a imagem do candidato, sua principal estratégia de governo, e também representa uma vantagem em relação ao adversário político. O objetivo deste artigo é compreender, a partir da interpretação de sequências discursivas do pronunciamento de Dilma Rousseff, os modos como a memória discursiva determina a ordem do enunciável no lema "Brasil, pátria educadora". Como arcabouço teórico-metodológico, recorre-se aos conceitos de memória discursiva e interdiscurso. Para tanto, abordam-se as características do discurso político e as especificidades da linguagem da propaganda. Os resultados indicam os efeitos de sentidos do lema, destacam o passado de uma pátria educadora para a elite e descortinam um presente fértil de ações efetivas do governo federal, apagando as contradições e apontando para um futuro prenhe de esperança na equidade social.

Palavras-chave: Análise do discurso. Discurso Político. Propaganda política. Slogan.

\begin{abstract}
Political propaganda uses communication techniques to materialize partisan discourses. The slogan is an example, since it mobilizes the discursive functioning on the forms of government of the State, the party ideologies, the image of the candidate, its main strategy of government, and also represents an advantage over the political adversary. The aim of this article is to understand, through the interpretation of discursive sequences of Dilma Rousseff's speech, the ways in which the discursive memory determines the order of the enunciable in the motto "Brazil, educating country". As a theoretical-methodological framework, the concepts of discursive memory and interdiscourse are used. To do so, the characteristics of the political discourse and the specificities of the language of the propaganda are approached. The results indicate the meaning effects of the motto, highlight the past of an educating homeland for the elite and unveil a fertile present of the federal government effective actions, erasing the contradictions and pointing to a future pregnant with hope of social equity.
\end{abstract}

Keywords: Discourse analysis. Political speech. Political advertising. Slogan.

Doutoranda em Letras pela Universidade Estadual de Maringá (UEM), Brasil. E-mail: tacia.rocha.f@gmail.com. ii Doutoranda em Letras pela Universidade Estadual de Maringá (UEM), Brasil. E-mail: Ivitoriano@geduem.com.br. iii Mestra em Letras pela Universidade Estadual de Maringá (UEM), Brasil. E-mail: flaviafcsb@gmail.com. 
EID\&A - Revista Eletrônica de Estudos Integrados em Discurso e Argumentação, Ilhéus, n. 15, jan./jun.2018.

\section{Introdução}

A propaganda política utiliza técnicas de comunicação para materializar os discursos partidários, seja na formulação, na circulação, na recepção ou nos efeitos dos discursos. Muito utilizado na divulgação de marcas, o slogan é um exemplo contundente de circulação de discursos, pois trata-se de um lema ou brado de guerra. Trocando os sintagmas "produto" e/ou "serviço" por "candidato" e/ou "parlamentar" e trocando "consumidor" e/ou "públicoalvo" por "eleitor" e/ou “cidadão", facilmente compreendemos como os manuais de redação publicitária definem e adaptam a funcionalidade do slogan a diferentes tipos de campanhas de comunicação (SANT'ANNA, 1996).

Para este texto, chamamos a atenção para o slogan do governo federal, gestão Dilma Rousseff (2015-2016): “Brasil, pátria educadora”. O lema faz surgir como acontecimento dado a ler, (re)estabelecendo os implícitos associados ao sistema de regularização anterior (ACHARD, 1999). Além de retomar, por meio da paráfrase, outros slogans do governo federal petista "Brasil, um país de todos" - gestão Lula (2003-2006; 2007-2010), e "Brasil, país rico é país sem pobreza” - gestão Dilma Rousseff (2011-2014) - há a tentativa de manter uma unidade discursiva com os pilares fundamentais do modelo de governo proposto pelo partido: a distribuição de renda e a diminuição da desigualdade no Brasil (ROUSSEFF, 2013). Contudo, essas e outras relações interdiscursivas não são tão óbvias. Nosso objetivo, neste artigo, é compreender, a partir da análise e interpretação de sequências discursivas do pronunciamento de Dilma Rousseff, os modos como a memória discursiva determina a ordem do enunciável no lema "Brasil, pátria educadora".

Para tanto, elencamos como referencial teórico autores fundamentais para a compreensão da memória discursiva, a começar por Pêcheux (1990; 1995; 1999) e seus comentadores - Orlandi (2009; 2012), Authier-Revuz (2004) e Maingueneau (1997). Tratamos ainda das características do discurso político com Piovezani (2009), e das especificidades da linguagem da propaganda, a partir das noções teóricas de Sant'Anna (1996), Queiroz e Manhanelli (2009) e Lupetti (2000).

\footnotetext{
${ }^{1} \mathrm{O}$ mandato foi impedido com a justificativa de crime de responsabilidade pela prática das chamadas "pedaladas fiscais" e pela edição de decretos de abertura de crédito sem a autorização do Congresso. Após 273 dias o processo foi encerrado em 31 de agosto de 2016 sem a perda dos direitos políticos de Dilma.
} 
EID\&A - Revista Eletrônica de Estudos Integrados em Discurso e Argumentação, Ilhéus, n. 15, jan./jun.2018.

Inicialmente, conceituamos o que é memória discursiva; em um segundo momento, discutimos as características do discurso político, bem como dos recursos da publicidade e propaganda usados na política; em um terceiro momento é apresentada a análise a partir do trajeto temático do slogan analisado no interior de um arquivo, para que finalmente possamos tecer nossas considerações finais.

\section{Memória e Interdiscurso: formulações feitas e já esquecidas}

Na segunda fase de sua teoria (AD-2), Pêcheux adota, com modificações, a noção de formação discursiva (FD), emprestada de Michel Foucault e com isso inicia uma ruptura com relação à noção de maquinaria estrutural fechada, pois a FD é constitutivamente invadida por elementos externos. Mas é somente na terceira fase da Análise de Discurso (AD-3) que o conceito de maquinaria é totalmente rompido. Isso porque é nessa fase que a noção de interdiscurso é introduzida para designar o exterior específico de uma FD. A partir daí passa-se a conceber o interdiscurso como um efeito da interpelação ideológica, atuando como fator determinante para a significação, a representação e para o simbólico.

O filósofo Pêcheux (1995) entende interdiscurso como um saber discursivo (palavras já ditas e esquecidas), mas que continuam presentes e que possibilitam que as nossas palavras façam sentido - algo fala antes, em outro lugar, de forma independente do discurso que é proferido na atualidade. Esse saber corresponde a algo "já dito", entretanto, ainda continua alinhavando os nossos discursos.

O interdiscurso é o "todo complexo com dominante das formações discursivas" (PÊCHEUX, 1995, p. 163), imbricado no complexo das Formações Ideológicas (FI), que toda a Formação Discursiva (FD) dissimula, na ilusão de transparência do sentido que nela se forma. É o lugar onde se constituem os objetos do saber (os enunciados). Com a memória discursiva, os enunciados pré-construídos podem ser operados na formação discursiva de cada sujeito e produzir novos discursos que estabelecem relações com tudo o que já foi dito, com o interdiscurso, com sua memória discursiva. Todo discurso se constitui a partir da memória e do esquecimento de outro.

Orlandi (2009, p. 31) vai ao encontro da teoria pecheutiana ao definir a memória discursiva como o interdiscurso que "[...] disponibiliza dizeres que 
EID\&A - Revista Eletrônica de Estudos Integrados em Discurso e Argumentação, llhéus, n. 15, jan./jun.2018.

afetam o modo como o sujeito significa uma situação discursiva dada". 0 saber discursivo não se aprende, mas produz seus efeitos por meio da ideologia e do inconsciente. Para a autora, o interdiscurso está articulado ao complexo de formações ideológicas.

Assim, a constituição determina a formulação, pois só podemos dizer (formular) se nos colocamos na perspectiva do dizível (interdiscurso, memória). Todo dizer, na realidade, se encontra na confluência dos dois eixos: o da memória (constituição) e o da atualidade (formulação). Esquecemos que outro sujeito disse determinada coisa, que apesar do anonimato, faz sentido em nossas palavras. Vemos, então, que a diferença entre interdiscurso e intertexto é que o primeiro é da "ordem do saber discursivo, memória afetada pelo esquecimento, enquanto que o último é a mera relação entre textos" (ORLANDI, 2009, p. 34).

Outra contribuição é a noção de interdiscurso em Authier-Revuz (2004) associada ao conceito de heterogeneidade constitutiva do discurso. A autora se ancora em outras duas abordagens: o dialogismo do círculo de Bakhtin e a psicanálise (por meio da leitura de Freud, marcada por Lacan).

$\mathrm{Na}$ perspectiva dialógica do discurso, o outro atravessa constitutivamente o um. O "outro é o princípio fundador da subjetividade" (AUTHIER-REVUZ, 2004, p. 36), é uma lei constitutiva do tecido de todo discurso, constituindo o discurso de forma heterogênea, passando pelo continuum das formas recuperáveis da presença do outro no discurso, das palavras dos outros sempre presentes no discurso. Esse ponto de vista se manifesta em uma renovação atual das perspectivas da análise de discurso, tanto pelo questionamento teórico de qualquer concepção homogeneizante da discursividade (PÊCHEUX, 1990) implicado nos procedimentos da análise automática do discurso quanto pelo reconhecimento da "heterogeneidade estrutural de qualquer formação discursiva".

Enquanto o dialogismo destrói a concepção de palavra homogênea, a psicanálise derruba a imagem de um sujeito 'pleno', que seria a causa primeira e autônoma. "O outro não é um objeto (exterior, do qual se fala), mas uma condição (constitutiva, para que se fale) do discurso de um sujeito falante que não é fonte-primeira desse discurso" (AUTHIER-REVUZ, 2004, p. 69). Trata-se de um sujeito dividido, clivado e interpelado pela ideologia. Não há centro de onde emanariam o sentido e a fala. Manter a ilusão de ser o centro é a função necessária e normal do ser sujeito de um enunciado. $O$ sujeito é um efeito de 
EID\&A - Revista Eletrônica de Estudos Integrados em Discurso e Argumentação, llhéus, n. 15, jan./jun.2018.

linguagem, pois "não é uma entidade homogênea, exterior à linguagem, que Ihe serviria para 'traduzir' em palavras um sentido do qual ele seria a fonte consciente" (AUTHIER-REVUZ, 2004, p. 63).

Maingueneau (1997) ressalta que após a retomada das ideias do Círculo de Bakhtin acerca da heterogeneidade de um discurso, a própria formação discursiva não pode ser concebida como um bloco compacto, tendo em vista que ela é porosa e instável, inconsistente e aberta. O interdiscurso passa a ser reconhecido como um processo de reconfiguração da formação discursiva que incorpora elementos pré-construídos, produzidos fora dela, sendo redefinida e redirecionada, provocando o apagamento, o esquecimento de determinados elementos. Um discurso, então, nasce "[..] de um trabalho sobre outros discursos" (MAINGUENEAU, 1997, p. 120 - grifos do autor). Portanto, o enunciado encontra-se numa rede discursiva 'vertical' de formulação, uma memória discursiva, e que serve de subsídio para a formulação dos slogans.

\section{Discurso político e os slogans}

O slogan é uma estratégia discursiva do campo da publicidade e propaganda, cujo objetivo é promover a disseminação de uma marca e a memorização desta por meio de uma sentença simples e direta. É utilizada para vender tanto produtos e serviços quanto comportamentos, ideias, e neste trabalho para reafirmar a imagem de um estilo de governo, veiculada pela propaganda política.

Contudo, para analisarmos o slogan de uma campanha de comunicação partidária, é primordial compreendermos as características do discurso político, já que é a partir dele que o slogan adquire as funções de reforçar, de atualizar, de transformar e de retomar os sentidos produzidos à comunicação partidária. Na segunda seção, discutimos as especificidades da linguagem da propaganda para a inserção do discurso político.

\subsection{Especificidades do discurso político}

Piovezani (2009) justifica a necessidade de se estudar as características do discurso como político por dois motivos: mesmo no âmbito da Análise do Discurso o sintagma "discurso político" é referenciado sem maiores especificações quanto às suas propriedades; e, também, pelo fato de o termo 
EID\&A - Revista Eletrônica de Estudos Integrados em Discurso e Argumentação, Ilhéus, n. 15, jan./jun.2018.

"político" ser empregado para designar um conjunto diversificado de atos de linguagem, sem distinguir o seu estatuto.

Assim, para tratar das características de um discurso dito político, Piovezani (2009, p. 131) inicia uma busca pela legitimidade do poder, a partir de um conjunto de crenças que lhe dê sustentação. Desse modo, "no discurso político, a simulação de um saber e de um poder visa a um fazer-crer e a um fazer-fazer, uma vez que ultrapassando o nível da convicção, deseja-se atingir o nível da ação" (PIOVEZANI, 2009, p. 131). O autor cita Christian Le Bart para resumir o conjunto de crenças em quatro ilusões necessárias para sustentar o discurso político:

a) supõe uma visão transparente e ordenada da complexa realidade social; b) busca constantemente a legitimidade, repetindo por diversas vias e maneiras que o agente político cumpre uma missão atribuída pelo 'povo' e destinada ao 'povo'; c) advoga uma hegemonia dos atores do campo político no que se refere ao governo e à gestão da sociedade; e d) esquece ou pretende fazer esquecer a diversidade das individualidades pessoais, em nome de 'interesses coletivos' (LE BART, 1998 apud PIOVEZANI, 2009, p. 139).

A primeira implica em considerar a realidade social transparente, na qual a realidade é dada a ler e classificada em coisas e pessoas, pessoas e grupos de forma binária, classificando tudo em bem/mal. A segunda ilusão, o campo político caracteriza-se por uma constante busca de legitimidade para garantir a governabilidade, na construção de um “"eu', ator político legítimo que alega um 'saber especializado e poder suficiente para intervir na realidade"” (PIOVEZANI, 2009, p. 135). Na terceira ilusão, a despeito da miséria e da insegurança, o saber e o poder convergem para a consolidação da legitimidade, e o discurso político afirma sua potência de intervir e controlar satisfatoriamente os fenômenos sociais. Por último, a quarta ilusão necessária para o discurso político é a soma dos cidadãos constituir uma comunidade, pela qual é viabilizada pela construção da identidade do seu interlocutor, fundamentada em uma pertença ideológica ou pela inscrição de determinados grupos.

Piovezani (2009) alerta sobre outro aspecto importante para a caracterização de um discurso político. O adjetivo "político" passou a qualificar toda dimensão discursiva, a partir dos anos 1970 no campo das ciências sociais. Nessa visada teórica, todos os discursos da sociedade seriam considerados como "políticos", regidos pelo "princípio segundo o qual 'tudo é político', porque pressupõe a existência de um conjunto de relações sociais de 
EID\&A - Revista Eletrônica de Estudos Integrados em Discurso e Argumentação, Ilhéus, n. 15, jan./jun.2018.

força em meio ao qual os discursos são produzidos e interpretados" (PIOVEZANI, 2009, p. 140). É preciso tratar da especificidade do qualificador "político" do discurso político ou até entender que o discurso político não existe.

Piovezani (2009) acrescenta ao conceito de campo, do sociólogo francês Pierre Bourdieu, a possibilidade de recorrer ao conceito de gêneros do discurso, do Círculo de Bakhtin, com o intuito de conceber que o enunciador é condicionado diferentemente pelas esferas pública e privada. Os enunciados são concretos e únicos, refletem as condições específicas e as finalidades de uma das esferas de atividade humana, e é construído pelo conteúdo temático, pelo estilo e pela construção composicional. Cada esfera de atividade humana elabora enunciados relativamente estáveis, os chamados gêneros do discurso.

A partir dessa concepção bakhtiniana, os gêneros do discurso seriam manifestados em "forma de programas do governo, pronunciamentos, declarações, entrevistas, debates, panfletos, cartas abertas, jingles, documentários, etc." (PIOVEZANI, 2009, p. 147, grifos do autor). Soma-se a esses gêneros cartas, cartões e panfletos político-publicitários ou projetos sociais feitos ou propostos, graças à incorporação de estratégias publicitárias ao campo político desde os anos 1950. O conteúdo temático é aquele que se repete nos gêneros discursos,

\footnotetext{
Uma vez que concebemos o discurso político como uma prática simbólica produzida, no interior do campo discursivo político, em circunstâncias públicas, por um enunciador legítimo ou em busca de legitimidade, que não se reduz a um "eu" pessoal, destinada a uma audiência que não corresponde a um interlocutor real, e cujo assunto em questão se refira direta ou indiretamente ao interesse comum de uma coletividade, acreditamos que seja o conteúdo temático a dimensão que se repete nesses diversos gêneros em que o discurso político se formula (PIOVEZANI, 2009, p. 147).
}

Além do conteúdo temático, os gêneros do discurso refletem as "condições específicas e as finalidades de cada uma das esferas da atividades humana" (PIOVEZANI, 2009, p. 148). Quando observamos o campo político, observamos que constitui as especificidades que caracterizam os discursos políticos, cujos referentes e mensagens devem ser públicos e atingir o público pretendido da identidade comunitária. Essa circulação não se reduz ao âmbito físico nem aos modos de transmissão e alcance, importantes para um discurso político. Para ganhar existência, deve ser propagado e 'publicizado', por meio de comunicação de massa que proporciona a recepção discursiva. Assim, a 
EID\&A - Revista Eletrônica de Estudos Integrados em Discurso e Argumentação, llhéus, n. 15, jan./jun.2018.

mídia pode servir tanto como uma instância privilegiada de produção e circulação de efeitos de verdade e rompimento com o estigma de mentiroso do discurso político, cristalizado no interdiscurso, quanto pode reforçar a mentira como uma propriedade constitutiva do campo político, cuja trajetória é tão antiga quanto intrincada nas relações de constituição social, o que the confere uma função verdadeiramente humana/política (COURTINE, 2006).

É preciso entender que o discurso midiático em geral "cria a ilusão de uma relação significativa entre causas e consequências para os fatos ocorridos" (MARIANI, 1996, p. 63) e, partir daí, dissimula e estabelece aspectos como a veracidade e a transparência do discurso midiático. Com efeito, naturalizam-se o sentidos, tornando-os “'evidentes', legítimos e necessários" (MARIANI, 1996, p. 51), bem como os discursos e os comportamentos que deles emanam.

\subsection{Campanha de propaganda política e o slogan}

Para que possamos compreender como o discurso político se organiza na superfície linguística da propaganda, propomos articular a análise do discurso à teoria da linguagem da propaganda. Sant'Anna (1996, p. 88) reforça que a propaganda é feita a partir da linguagem em consonância com a psicologia humana, nesse sentido "quanto mais conhecemos sobre o valor das palavras, sobre as necessidades, desejos, e impulsos humanos e as emoções que desencadeiam, mais saberemos sobre a técnica de persuasão e seu modo de operar". Com isso, o autor reforça a importância de conhecer o chamado "consumidor típico", ou no caso da propaganda política, o eleitor típico.

Piovezani (2009) concorda com o estabelecimento do público-alvo ao dizer que um discurso para ser político deve atingir o público pretendido, isto é, uma nação. Para se conhecer o eleitor, conta-se com pesquisas que detectam:

[...] as qualidades já enxergadas no candidato e as valorizam, ou apregoam um conceito que se deseje reforçar sobre o candidato ou sobre sua plataforma proposta, ou um desejo, necessidade, anseio ou precisão da população naquele momento (QUEIROZ; MANHANELLI, 2009, p. 2).

Esses dados orientam na criação da propaganda política como no slogan "Sem medo de ser feliz", na campanha de Lula para as eleições de 1990, após os publicitários detectarem nas pesquisas que a classe média tinha medo de votar em Lula (QUEIROZ; MANHANELLI, 2009). 
EID\&A - Revista Eletrônica de Estudos Integrados em Discurso e Argumentação, llhéus, n. 15, jan./jun.2018.

Os anseios do povo foram traduzidos em promessas de campanha de comunicação por meio de uma unique selling proposition - proposta única de venda - que passou a representar uma qualidade ou virtude do candidato, a proposta de governo ou a ideologia partidária; o anúncio, também, pode ganhar uma força extra com o uso de celebridades apoiando aquele candidato/parlamentar eleito. Ao invés do produto, o referente é o político ou o partido e/ou governo, no caso da propaganda institucional.

Para além das informações que orientam o discurso a ser veiculado, o tipo de propaganda política determina o que pode e o que não pode ser dito. Há três tipos de propaganda política: a intrapartidária, a partidária e a eleitoral e, para Gomes (CÂNDIDO, 2010, p. 333), inclui a propaganda institucional.

A primeira é usada dentro do partido para mobilizar os integrantes e constituir uma unidade partidária. A propaganda eleitoral é realizada, pontualmente, na época das eleições. O período da propaganda eleitoral se inicia em julho do ano da eleição e é finalizado na véspera do pleito. A partidária é voltada ao público externo, eleitores, ou não, com vista à divulgação dos pilares que constituem seu sistema de crenças, direcionada ao intuito de manter vivo na mente do eleitor a legenda. Já a institucional é aquela que divulga a empresa/governo como um todo, nessa conjuntura, caracteriza-se por conceituar o governo, fixar a imagem, informar os pilares, objetivando o estabelecimento e reconhecimento de sua marca governamental daquela gestão. Campanhas de serviços públicos e a campanha de publicização de medidas governamentais podem ser consideradas campanhas institucionais (LUPETTI, 2000).

\section{Análise do slogan: "Brasil, pátria educadora"}

Partindo-se do princípio de que no texto publicitário os sentidos podem ser produzidos a partir dos enunciados construídos, tomar-se-á como corpus o slogan "Brasil, pátria educadora", sentença que se repete em todas peças de comunicação do governo em gêneros do discurso como panfletos, vinhetas de abertura e encerramento de pronunciamentos, papelaria, sites e redes sociais oficiais, cenário das coletivas com o parlamentar, em especial, da presidência da República. Em síntese, repete-se na propaganda de todos Ministérios, "faz parte do que estamos chamando Língua de Estado, pois representa o 'pensamento' do Estado" (ORLANDI, 2012, p. 125). 
EID\&A - Revista Eletrônica de Estudos Integrados em Discurso e Argumentação, llhéus, n. 15, jan./jun.2018.

Ao optarmos pelo dispositivo teórico metodológico da Análise do Discurso, estamos em consonância com Orlandi (2012), pois fazemos um deslocamento da relação biopsicológica esclarecida por Pêcheux nas três fases (seção anterior), e adotamos referências teóricas da publicidade para analisar as "formas históricas de assujeitamento do indivíduo", desenvolvidas no interior do capitalismo. Retomando Courtine (apud PÊCHEUX, 1999), a noção de memória discursiva é apresentada como intrínseca à existência histórica do enunciado, no seio de práticas discursivas reguladas pelos aparelhos ideológicos, capaz de dar origem a atos novos, no sentido de que toda a produção discursiva acontece em uma conjuntura dada e coloca em movimento formulações já ditas.

O gesto de leitura proposto inclui tanto o movimento de analisar o slogan, a rede de sentidos e a filiação a uma memória, quanto o movimento de analisar suas relações com os enunciados conhecidos na atualidade. Para tanto, vamos trabalhar o enunciado "Brasil, pátria educadora", a partir de uma sequência discursiva retirada da matéria veiculada na TV do governo federal NBR, com o objetivo de analisarmos a partir do recorte do pronunciamento editado pelo veículo do governo (TVNBR, 2015).

(SD 1) Repórter (1'35): No discurso, aqui no congresso nacional, a presidenta Dilma Rousseff anunciou o lema do segundo mandato, iniciado nesta quintafeira. A educação vai ser a prioridade.

(SD 2) Dilma Rousseff (1'45): Ao bradarmos "Brasil, pátria educadora" estamos dizendo que a educação será a prioridade das prioridades, mas, também, que devemos buscar, em todas as ações do governo, um sentido formador, uma prática cidadã, um compromisso de ética e um sentimento republicano. Só a educação liberta um povo e lhe abre as portas de um futuro próspero.

Iniciando a busca de uma memória discursiva a partir da visão histórica da educação, Saviani (2008) salienta que essa não ganhou a atenção e prioridade devida pelos governantes, embora desde meados do século XIX a constituição dos chamados 'sistemas nacionais de ensino' tenham se inspirado no "princípio de que a educação é direito de todos e dever do Estado" (SAVIANI, 2008, p. 5). Encontramos a memória de "prioridade" na concepção de governo que ao estabelecer metas, deve hierarquizá-las em um painel de importância. A palavra é destacada tanto na fala da repórter quanto no discurso da presidenta.

Historicamente, a educação no Brasil pode ser divida em quatro fases: 1 ) a pedagogia católica dos jesuítas (1549-1759); 2) a pedagogia laica (1759-1932) 
EID\&A - Revista Eletrônica de Estudos Integrados em Discurso e Argumentação, llhéus, n. 15, jan./jun.2018.

desenvolve-se em paralelo à pedagogia católica; 3) a emergência da pedagogia nova (1932-1969); 4) de 1969 à contemporaneidade emerge a pedagogia produtivista, que visa atender às necessidades de mercado, próprio de uma sociedade capitalista (SAVIANI, 2013). Nessas quatro fases, o préconstruído "Brasil não é uma pátria educadora" ou, ainda, "Brasil precisa ser uma pátria educadora” é reiterado. Esmiuçando o pré-construído, retomemos alguns pormenores de cada fase da educação no Brasil.

No início da colônia, o objetivo principal da educação era catequizar os índios para reagir à Reforma Protestante. Em 1759, os jesuítas foram expulsos de Portugal e da colônia e o marquês de Pombal iniciou uma reforma da Educação para modernizar o reino de Dom José I (1714-1777), a chamada Reforma Pombalina. Para substituir os padres, Pombal criou as aulas régias ministradas por professores públicos formados a partir de cursos preparatórios. Tratava-se da pedagogia laica. Como as nomeações demoraram, aconteceram somente em 1774, no Rio de Janeiro, quem tinha condições recorria a professores particulares e os demais permaneciam sem escola (SCACHETTI, 2013).

No século XIX, surgiu o sistema educacional para atender aos interesses da nova classe que se consolidava no poder - a burguesia - para superar a situação de opressão do "Antigo Regime" e ascender à sociedade fundada no contrato social celebrado "livremente". Em virtude dessa escola não ter se universalizado nem todos terem sido bem-sucedidos, ela foi denominada Escola Tradicional. Nessa concepção escolar, a marginalidade é causada pela ignorância (SAVIANI, 2008).

A partir do final do século XIX, foram formuladas críticas à pedagogia tradicional dando origem ao escolanovismo, criado segundo as diretrizes da Escola Tradicional. Essa teoria mantinha a crença no poder da escola para equalização social. Segundo Saviani (2008), nessa concepção a marginalidade é causada pela rejeição, pois o indivíduo não está integrado e não se sente aceito pela sociedade. Embora pretendeu-se generalizar essa nova perspectiva ao âmbito dos sistemas escolares, ela ficou restrita à forma de escolas experimentais ou como núcleos raros, muito bem equipados e circunscritos aos pequenos grupos de elite.

Embora o escolanovismo tenha sido a concepção teórica dominante, "portadora de todas as virtudes e de nenhum vício" (SAVIANI, 2008, p. 10), ao passo que a Pedagogia Tradicional foi a "portadora de todos os vícios e de 
EID\&A - Revista Eletrônica de Estudos Integrados em Discurso e Argumentação, llhéus, n. 15, jan./jun.2018.

nenhuma virtude" (SAVIANI, 2008, p. 10), ela entrou em declínio após a primeira metade do século XX. Se por um lado insurgiram tentativas de se desenvolver uma espécie de "Escola Nova Popular", cujos representantes são as pedagogias de Freinet e de Paulo Freire, por outro surgiu uma nova teoria educacional, cuja preocupação está na eficiência instrumental. Articulou-se, aqui, uma nova teoria educacional: a pedagogia tecnicista.

Nesse sentido, Saviani (2008) salienta que o marginalizado é o incompetente (no sentido técnico da palavra), o ineficiente e improdutivo. Essa pedagogia foi constituída a partir do pressuposto da neutralidade científica e inspirada nos princípios de racionalidade, eficiência e produtividade. Passa-se a reordenar o processo educativo para torná-lo objetivo e operacional, imitando o modelo de trabalho fabril. Nesse modelo aparecem propostas pedagógicas como o enfoque sistêmico, o microensino, 0 telensino, a instrução programada, as máquinas de ensinar etc. A pedagogia tecnicista precarizou a constituição humanística dado que o "conteúdo do ensino tornou-se ainda mais rarefeito e a relativa ampliação das vagas tornouse irrelevante em face dos altos índices de evasão e repetência" (SAVIANI, 2008, p. 12).

$\mathrm{Na}$ educação da contemporaneidade, tomamos Chaui (2014) para explicitar essa pedagogia voltada para a produtividade, integrando a educação à política neoliberal, instaurando a ideologia da competência. $O$ modelo tecnocientífico foi instituído em grandes empresas capitalistas, fazendo com que as ciências passassem a participar no processo produtivo, tal "mudança fez surgir a expressão sociedade do conhecimento para indicar que a economia contemporânea se funda sobre a ciência e a informação nos processos produtivos e financeiros, bem como em serviços como a educação, a saúde, a cultura e o lazer" (CHAUI, 2014, p. 56). É nesse contexto de um Brasil, que, ainda, não é pátria educadora, mas está em busca de um porvir na educação.

No pré-construído, o slogan revitaliza a memória de um país elitista que pode ser transformado pelas políticas sociais encabeçadas pela gestão petista. É na Sociedade do Conhecimento, cuja implantação iniciou na Europa no início dos anos 1990, sob a alcunha de Sociedade da Informação e chegou ao Brasil, em dezembro de 1998, que a educação passa a ser assunto de responsabilidade compartilhada entre três setores: governo, iniciativa privada e sociedade civil. 
EID\&A - Revista Eletrônica de Estudos Integrados em Discurso e Argumentação, llhéus, n. 15, jan./jun.2018.

Discursivamente, na gestão das Sociedades do Conhecimento, assim nomeada pela "Cúpula Mundial da Sociedade da Informação" (CMSI), em 2003 e 2005, a aprendizagem está no centro e se caracteriza como uma das grandes linhas de ação do programa brasileiro por nós destacado (MANSELL, 2015). A diferença entre "Sociedade da Informação" e "Sociedade do Conhecimento" é que a primeira dá ênfase no conteúdo do trabalho, e a segunda prioriza os sujeitos que devem possuir qualificações conquistadas a partir da aprendizagem para o exercício do seu trabalho (AMBROSI; PEUGEOT; PIMENTA, 2005). O Brasil precisa ser uma pátria educadora para se alinhar às necessidades do modelo neoliberal.

Ainda pelo interdiscurso podemos recuperar os sentidos já-ditos no sintagma "pátria". Diferente dos outros dois slogans do governo federal petista que usaram a palavra "país" - "Brasil, um país de todos" e "Brasil, país rico é país sem pobreza" - no slogan em análise temos a palavra pátria, do latim significa “terra natal”. Etimologicamente, pátria nos leva à pater, "pai”, a mesma palavra que derivou padre, paternalismo, patriarca, patriarcalismo, patrício e compatriota (RODRIGUES 2010). Nesse sintagma, observamos o efeito de sentido de um Brasil acolhedor, de pai que protege seu filho (cidadão), oferece condições melhores de educação, fazendo com que retomemos o sentido de pátria e patriotismo presentes no hino nacional do Brasil:

(SD 3) “Ó pátria amada,/ Idolatrada,/ Salve! Salve!”

Pela memória discursiva conseguimos recuperar mais um aspecto importante - a retomada de políticas sociais em consonância com políticas internacionais. O slogan "Brasil, pátria educadora" retoma o segundo “Objetivo do Milênio" (ODM) "atingir o ensino básico universal”, estabelecido pela “Organização das Nações Unidas” (ONU) nos anos 2000, com prazo de vencimento em 2015. O ODM é traduzido pelo "Programa de Desenvolvimento das Nações Unidas" (PNUD) por meio de duas metas: "1) garantir que, até 2015, todas as crianças, de ambos os sexos, terminem um ciclo completo de ensino básico; 2) garantir que, até 2015, as crianças de todas as regiões do país, independentemente de cor/raça e sexo, concluam o ensino fundamental" (PNUD, 2000).

O efeito de sentido de universalização é provocado pela paráfrase discursiva em "todas as crianças" e "todas as regiões", na primeira e segunda 
EID\&A - Revista Eletrônica de Estudos Integrados em Discurso e Argumentação, Ilhéus, n. 15, jan./jun.2018.

meta do ODM, respectivamente. A memória discursiva de "universalização" do Ensino Fundamental pode ser recuperada ao ler na íntegra o pronunciamento de lançamento do slogan, marcado como uma meta do governo (ROUSSEFF, 2015).

O pré-construído "Brasil, precisa ser uma pátria educadora" também é recuperado nas metas para a educação constantes no "Plano Nacional de Educação" (PNE), cuja vigência é de 2011 a 2020 (início do primeiro mandato de Dilma). O PNE funciona como tática para atingir o segundo ODM. Em nosso gesto de leitura, o sintagma "universalização" ganha relevância, pois é ele que materializa o discurso da prioridade na educação. Destacamos do texto da Lei do PNE ( $n^{\circ}$ 13.005/2014), publicada em 25 de junho de 2014 os enunciados: "erradicação do analfabetismo"; "universalização do atendimento escolar"; "superação das desigualdades educacionais"; "melhoria da qualidade da educação". Essa lei vai pelo interdiscurso aparecer nas primeiras quatro metas, na qual o sintagma universalização aparece nos níveis: Educação Infantil (4 a 5 anos), Fundamental (6 a 14 anos), Médio (15 a 17 anos) e Educação Especial (4 a 17 anos). Nas demais metas, há menção dos níveis Superior, Pós-graduação e Ensino Técnico.

Finalizamos a análise da memória discursiva ao recuperarmos a primeira vez em que o enunciado "Brasil, pátria educadora" foi enunciado pelo governo, em pronunciamento oficial ao Dia do Trabalho (trocado pelo sintagma "dia dos trabalhadores"), em primeiro de maio de 2013. No pronunciamento, a presidenta traz a memória da Sociedade da Informação por meio do discurso que a educação deve ser responsabilidade compartilhada entre três setores: governo, iniciativa privada e sociedade civil.

(SD 4) [...] Somente a pressão de todos vai fazer os governos, as empresas, as igrejas, os sindicatos, em suma, toda a sociedade trabalharem ainda mais pela educação. Somente assim poderemos gritar, em uma só voz, uma nova marca de fé e amor para nosso país. Poderemos gritar, do fundo do nosso coração: Brasil, pátria educadora!

Viva o Brasil! Viva a trabalhadora! Viva o trabalhador brasileiro!

Obrigada e boa noite (ROUSSEFF, 2013, grifos nossos).

O pré-construído "Brasil não é uma pátria educadora" é apagado pelas séries de iniciativas do governo federal, revitalizando o pré-construído "O Brasil precisa ser uma pátria educadora": transferência de todos os royalties do petróleo e recursos do pré-sal para investimento em educação; programa Ciência sem Fronteiras; implantação da escola de tempo integral; programa de 
EID\&A - Revista Eletrônica de Estudos Integrados em Discurso e Argumentação, llhéus, n. 15, jan./jun.2018.

modernização das escolas; bolsas do "Programa Universidade Para Todos" (ProUni) e financiamento do "Fundo de Financiamento Estudantil" (FIES); "Programa Nacional de Acesso ao Ensino Técnico e Emprego" (Pronatec); política de cotas das escolas públicas em Universidades Federais. Na opacidade, o slogan por nós analisado, tenta apagar a memória de um país marcado pela injustiça social e díspar na distribuição de renda, para fazer viver o porvir de um país em que reine a equidade social, na esperança de uma já possível e atual pátria educadora.

\section{Considerações Finais}

Como discutimos ao longo deste texto, na perspectiva da Análise do Discurso, os sentidos são condicionados dada a forma com que os discursos se inscrevem na língua e na história, nesse sentido, a incompletude do discurso conduz o sujeito a mergulhar na exterioridade, na história para inscrevê-la na continuidade interna do discurso, ao fazê-lo, traz para seu discurso o falado antes, em outro espaço/tempo. Isso constitui o que Pêcheux (1995) chama de interdiscurso, o qual fornece materiais para uma formação discursiva.

No duplo movimento de análise feito em nosso gesto de leitura foi possível identificar os efeitos de sentido que o slogan provoca e sintetiza: ao mesmo tempo que ele traz consigo a memória discursiva do passado de uma pátria educadora apenas para uma parcela da população, a elite, ele aponta para um presente fértil de ações efetivas do governo federal e prenhe de esperança de um futuro inclusivo.

Acreditamos que nosso gesto de leitura pôde sustentar nossa hipótese inicial de que há, por meio do slogan "Brasil, pátria educadora", a tentativa de manter uma unidade discursiva na comunicação do governo federal com os pilares fundamentais do modelo de governo proposto pelo partido: a distribuição de renda e a diminuição da desigualdade no Brasil. O slogan é o que Orlandi (2012) chama Língua de Estado, pois representa as formas de ação do Estado. Nosso objetivo não foi exaurir todas as possibilidades de produção de sentidos, porque em Análise do Discurso os sentidos sempre podem ser outros. Somado a isso, visualizamos outros enunciados que podem implementar outra possibilidade de análise. 
EID\&A - Revista Eletrônica de Estudos Integrados em Discurso e Argumentação, Ilhéus, n. 15, jan./jun.2018.

\section{Fontes}

MINISTÉRIO A EDUCAÇÃO. Planejando a Próxima Década: conhecendo as 20 metas do Plano Nacional de Educação. Publicado em 2014. Disponível em: <http://pne.mec.gov.br/images/pdf/pne_conhecendo_20_metas.pdf>. Acesso em: 15 jan. 2018.

PRESIDÊNCIA DA REPÚBLICA. Lei do PNE (n 13.005/2014). Disponível em: <http://www.planalto.gov.br/CCIVIL_03/_Ato2011-2014/2014/Lei/L13005.htm>. Acesso em: 15 jan. 2018.

PROGRAMA DAS NAÇÕES UNIDAS PARA O DESENVOLVIMENTO (PNUD). Atingir O ensino básico universal, 2000. Disponível em: <http://www.pnud.Org.br/ODM2.aspx>. Acesso em: 15 jan. 2018.

ROUSSEFF, Dilma. Pronunciamento à nação da Presidenta da República, Dilma Rousseff, em cadeia nacional de rádio e TV, sobre o Dia do Trabalho. Portal Planalto. Brasília, 01 mai. 2013. Disponível em: <http://www2.planalto.gov.br/acompanhe-oplanalto/discursos/discursos-da-presidenta/pronunciamento-a-nacao-da-presidentada-republica-dilma-rousseff-em-cadeia-nacional-de-radio-e-tv-sobre-o-dia-do-trabalho1>. Acesso em: 15 jan. 2018.

ROUSSEFF, Dilma. Discurso da Presidenta da República, Dilma Rousseff, durante Compromisso Constitucional perante o Congresso Nacional. Portal Planalto. Brasília, 01 jan. 2015. Disponível em: <http://www2.planalto.gov.br/acompanhe-oplanalto/discursos/discursos-da-presidenta/discurso-da-presidenta-da-republica-dilmarousseff-durante-compromisso-constitucional-perante-o-congresso-nacional-1>. Acesso em: Acesso em: 15 jan. 2018.

TVNBR. Dilma Rousseff toma posse e anuncia lema do novo governo: "Brasil, pátria educadora”. Publicado em 02 jan. 2015. Disponível em: <https://www.youtube.com/watch?v=WpfdooXd_b8>. Acesso em: 15 jan. 2018.

\section{Referências}

ACHARD, Pierre [et al]. Papel da memória. Trad. e Intr. José Horta Nunes. Campinas: Pontes, 1999.

AMBROSI, Alain; PEUGEOT, Valérie; PIMENTA, Daniel (Org.). Desafios de palavras: enfoques multiculturais sobre as sociedades da informação. França: C\&F Éditions, 2005 .

AUTHIER-REVUZ, Jacqueline. Entre a Transparência e a Opacidade: um estudo enunciativo do sentido. Rev. tec. e trad. Leci Borges Barbisan [et al]. Porto Alegre: EDIPUCRS, 2004.

CÂNDIDO, Joel José. Direito Eleitoral Brasileiro. 14. ed. São Paulo/SP: Edipro, 2010. 
EID\&A - Revista Eletrônica de Estudos Integrados em Discurso e Argumentação, Ilhéus, n. 15, jan./jun.2018.

COURTINE, Jean-Jacques. O mentir verdadeiro. Tradução Mônica G. Zoppi-Fontana e Roberto Leiser Baronas. Campinas: Pontes, 2006.

CHAUÍ, Marilena. A ideologia da competência. In: ROCHA, André (Org.). A ideologia da competência. Belo Horizonte: Autêntica Editora, 2014.

LUPETTI, Marcélia. Planejamento de comunicação. São Paulo: Futura, 2000.

MAINGUENEAU, Dominique. Novas tendências em análise do discurso. Trad. Freda Indursky. 3. ed. Campinas: Pontes, Ed.Unicamp, 1997.

MANSELL, Robin. Renovando a visão das sociedades do conhecimento para a paz e o desenvolvimento sustentável. Organização das Nações Unidas para a Educação, a Ciência e a Cultura - UNESCO. Trad. Melissa Nicolosi e Gustavo Pugliesi Sachs. São Paulo: Comitê Gestor da Internet no Brasil, 2015.

MARIANI, Bethania. 0 comunismo imaginário: Práticas discursivas da imprensa sobre o PCB (1922 - 1989). 1996. 256 f. Tese (Doutorado em Linguística) - Instituto de Estudos da Linguagem, Unicamp: Universidade Estadual de Campinas, 1996.

- Discurso e instituição: a Imprensa. Rua - Revista do núcleo de Desenvolvimento da Criatividade, Campinas, n.5, p.47-61, mar. 1999.

ORLANDI, Eni Puccinelli. Análise de Discurso: princípios \& procedimentos. 8.ed. Campinas: Pontes, 2009.

. Propaganda política e língua de estado - Brasil país de todos. In: ORLANDI. Discurso em Análise: Sujeito, Sentido, Ideologia. Campinas: Pontes, 2012. p. 107-128.

PÊCHEUX, Michel. A análise de discurso: três épocas (1983). In: GADET, Françoise; HAK, Tony (Org.). Por uma análise automática do Discurso: uma introdução à obra de Michel Pêcheux. Trad. Bethania Mariani et al. Campinas: Editora da Unicamp, 1990. p. 311-319.

. Semântica e discurso: uma crítica à afirmação do óbvio. Trad. Eni Pulcinelli Orlandi et al. 2. ed. Campinas: Editora da Unicamp, 1995.

. Papel da memória. In: ACHARD, Pierre et al. Papel da memória. Trad. e Intr. José Horta Nunes. Campinas: Pontes, 1999. p. 49-57.

PIOVEZANI, Carlos. Os elementos para uma caracterização do discurso político. . Verbo, corpo e voz: dispositivos de fala pública e produção de verdade no discurso político. São Paulo: UNESP, 2009. p. 129-158.

QUEIROZ, Adolpho; MANHANELLI, Carlos. Breve história dos slogans políticos nas eleições do Brasil republicano. Signos do Consumo, v.1, n.2, p. 235-253, 2009.

RODRIGUES, Sérgio. A pátria e a ‘mátria’. Veja.com. São Paulo: 11 set. 2010. 
EID\&A - Revista Eletrônica de Estudos Integrados em Discurso e Argumentação, Ilhéus, n. 15, jan./jun.2018.

SANT'ANNA, Armando. Propaganda: teoria, técnica e prática. 7. ed. Ver. São Paulo: Pioneira, 1996. (Biblioteca Pioneira de arte, comunicação, arquitetura e urbanismo)

SAVIANI, Dermeval. Escola e democracia. Ed. comemorativa. Campinas: Autores Associados, 2008.

. Aberturas para a história da educação: do debate teórico-metodológico no

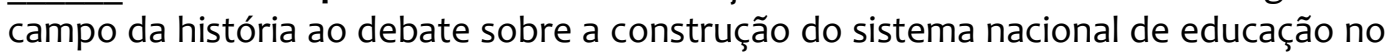
Brasil. Campinas: Autores Associados, 2013.

SCACHETTI, Ana Ligia. História da Educação no Brasil. Revista Nova Escola. Edição 263, junho/julho, 2013. (Série especial) Disponível em: <http://revistaescola.abril.com.br/formacao/serie-especial-historia-educacao-brasil750345.shtml>. Acesso em: 15 jan. 2018.

Forma de citação sugerida:

ROCHA, Tacia; VITORIANO-GONÇALVES, Luana; BARBOSA, Flávia Cristina Silva. Brasil, pátria educadora: memória discursiva e interdiscurso na tessitura da língua de Estado. EID\&A - Revista Eletrônica de Estudos Integrados em Discurso e Argumentação, Ilhéus, n. 15, p. 226-243, jan./jun.2018.

Recebido em: 28/02/2018

Aprovado em: 15/06/2018 